\title{
Make every mother and child count: a retrospective analysis of maternal mortality at medical college tertiary care hospital, Tamilnadu, India
}

\section{Rajarajeswari R.*, Poovathi M.}

\begin{abstract}
Department of Obstetrics and Gynaecology, Raja Mirasudar Hospital, Thanjavur Medical College, Thanjavur, Tamilnadu, India
\end{abstract}

Received: 24 August 2016

Accepted: 24 September 2016

\section{*Correspondence:}

Dr. Rajarajeswari R.,

E-mail: drrrrpanju@gmail.com

Copyright: (C) the author(s), publisher and licensee Medip Academy. This is an open-access article distributed under the terms of the Creative Commons Attribution Non-Commercial License, which permits unrestricted non-commercial use, distribution, and reproduction in any medium, provided the original work is properly cited.

\begin{abstract}
Background: Maternal mortality is a human development indicator. Maternal deaths have serious implication on the family, society and nation. This study is aimed to study the determinants, common causes and recommendations for the prevention of possible causes of maternal mortality.

Methods: A retrospective observational study of all maternal deaths for one year period from August 2014 to July 2015 was done in the Department of Obstetrics and Gynaecology, Raja Mirasudhar Hospital, Thanjavur Medical College, Thanjavur, Tamilnadu, India.

Results: Over the study period there were 29 maternal deaths out of 14898 deliveries with 14220 live births amounting to a maternal mortality ratio of 204 per 100000 live births. Hypertensive disorders complicating pregnancy were the leading causes of maternal mortality amounting to $40 \%$, while others were haemorrhage - $31 \%$, anaemia with failure $17.2 \%$, heart disease complicating pregnancy $6.4 \%$, sepsis $3.2 \%$ and other causes $3.2 \%$. Out of 29 maternal deaths $64.3 \%$ were in the age group $21-30$ years and $75.7 \%$ belonged to lower socio economic status.

Conclusions: The Maternal mortality ratio in our study was 204 per 100000 live births. Of these the Maternal Mortality Ratio due to intramural deaths was 70 per 100000 live births and Maternal Mortality Ratio due to extra mural deaths (late referral) was 134per100000live births. Hypertensive disorders complicating pregnancy (40\%) and its complications mainly HELLP $(72.7 \%)$ and eclampsia $(37.3 \%)$ were the most common cause of maternal deaths. Facility based maternal death review and State based maternal death review has contributed a lot in the analysis of the factors causing and compounding maternal mortality and reduction of maternal mortality and its ratio in Tamilnadu.
\end{abstract}

Keywords: Haemorrhage, Hypertensive disorders complicating pregnancy, Maternal mortality ratio, Maternal death audit

\section{INTRODUCTION}

Maternal mortality is universally considered as human development indicator in a country and determines the health status of the people. Maternal mortality as defined by WHO is "the death of any woman while being pregnant or within 42 completed days of termination of pregnancy, irrespective of the duration and the site of pregnancy from any cause related to or aggravated by the pregnancy or its management but not from accidental or incidental causes". Maternal mortality is defined internationally, as maternal deaths per 100000 live births. Direct maternal death is the result of a complication of pregnancy, delivery, or their management. Indirect maternal death is a pregnancy related death in a patient with pre-existing or newly developed health problem. 
The maternal mortality in India is 167 per 100000 live births (SRS 2011-2013) in comparison to 9 per 100000 in developed countries. ${ }^{2}$ Causes of maternal death vary in different regions of India. In southern India haemorrhage is the leading cause of maternal deaths followed by hypertensive disorders complicating pregnancy, sepsis, and anaemia. In North East India hypertensive disorders are the leading cause followed by haemorrhage, sepsis and anaemia. $^{2}$

WHO estimates show that $17 \%$ (50000) of world's maternal deaths are in India, with a woman dying every five minutes. Although India has achieved a 59\% reduction in maternal mortality as compared to1990 levels, it is still behind World Health Organisation's fifth millennium development's Goal (MDG 5) of $75 \%$ reduction of 1990 levels by 2015 which comes out to be approximately $5.5 \%$ reduction per year. ${ }^{3}$

In India southern states like Kerala (61 per 100000), Maharashtra (68 per 100000) and Tamilnadu (79 per 100000) have lower maternal mortality ratio compared to northern. States like Assam (300 per 100000), Uttar Pradesh (292 per 100000) which have a high maternal mortality ratio. ${ }^{4}$ Tamilnaduis still further trying to reduce its maternal mortality ratio by vision Tamilnadu 2023 where it targets to achieve a reduction in maternal mortality ratio to 45 by $2012-2017$ and to 25 by 2017 2023. ${ }^{2}$ The lower maternal mortality ratio in South India and especially Tamilnadu is probably due to Facility Based Maternal Death Review (FBMDR) and State high maternal mortality ratio held maternal death review by State health society as per NRHM guidelines. ${ }^{5}$ Facility based maternal death review is to be done at every institute level to find out the deficit in services and compounding factors and thus help in reduction of maternal deaths. ${ }^{6}$ To reduce maternal deaths we have to count beyond the numbers and review each and every maternal death for its possible causes and contributory factors many of which are avoidable. ${ }^{7}$

\section{METHODS}

Maternal deaths in the Department of obstetrics and gynaecology, Raja Mirasudar Hospital, Thanjavur Medical College, Thanjavur, Tamilnadu during the study period from August 2014 to July 2015 were evaluated. There were 29 maternal deaths amongst 14220 live births. The individual records of all 29 maternal deaths were extracted from patient's case notes, hospital records and maternal death review forms by state health society were analysed and reviewed in respect to maternal age, parity, booking status, residence, referral, socio economic class, Admission death interval, interventions carried out, direct and indirect cause of death, reason for referral and other socio demographic factors. The definition of maternal death by WHO has been used throughout the study.

No autopsy was done in maternal death cases due to socio religious reasons and hence autopsy reports to confirm the cause of death were not available in our study. Incidental and fortuitous causes of maternal death were excluded.

\section{RESULTS}

Table 1: Different characteristics of study group.

\begin{tabular}{|c|c|c|c|}
\hline Characteristics & & No. (of 29) & Percentage \\
\hline \multirow{3}{*}{ Residence } & Rural & 14 & 48.5 \\
\hline & Urban & 5 & 17.5 \\
\hline & Nomadic & 10 & 34 \\
\hline \multirow{3}{*}{ Age } & $<20$ & 2 & 6.8 \\
\hline & $20-29$ & 18 & 64.3 \\
\hline & $>/=30$ & 9 & 30.9 \\
\hline \multirow{2}{*}{ Socio economic strata } & Lower & 22 & 75.7 \\
\hline & Middle & 7 & 24.3 \\
\hline \multirow{2}{*}{ Parity } & Multi & 20 & 69.1 \\
\hline & Primi & 9 & 30.9 \\
\hline \multirow{2}{*}{ Spacinginmulti } & $<3 y r s$ & 16 & 85 \\
\hline & $>3 \mathrm{yrs}$ & 4 & 15 \\
\hline \multirow{2}{*}{ Booking Status } & Booked & 23 & 79.4 \\
\hline & Unbooked & 6 & 20.6 \\
\hline \multirow{5}{*}{ AN Care provided } & GHQH & 13 & 45 \\
\hline & PHC & 9 & 30.9 \\
\hline & $\mathrm{PNH}$ & 3 & 10.3 \\
\hline & $\mathrm{RMH}$ & 2 & 6.8 \\
\hline & NONE & 2 & 6.8 \\
\hline \multirow{2}{*}{ Educational status } & Illiterate & 6 & 20.6 \\
\hline & Primary School & 8 & 27.5 \\
\hline
\end{tabular}




\begin{tabular}{|c|c|c|c|}
\hline & $\begin{array}{l}\text { High School } \\
\text { Graduate }\end{array}$ & $\begin{array}{l}12 \\
3\end{array}$ & $\begin{array}{l}41.6 \\
10.3\end{array}$ \\
\hline Period of death & $\begin{array}{l}\text { Antepartum } \\
\text { Intrapartum } \\
\text { Postpartum }<24 \text { hours } \\
\text { Postpartum }>24 \text { hours }\end{array}$ & $\begin{array}{l}3 \\
1 \\
3 \\
19\end{array}$ & $\begin{array}{l}10.3 \\
3.4 \\
10.3 \\
76\end{array}$ \\
\hline Type of Intervention/delivery & $\begin{array}{l}\text { Abortion - MVA } \\
\text { Undelivered } \\
\text { Vaginal delivery } \\
\text { LSCS } \\
\text { (Peripartum hysterectomy) } \\
\text { Relaparotomy and } \\
\text { Hysterectomy }\end{array}$ & $\begin{array}{l}1 \\
3 \\
5 \\
13 \\
7\end{array}$ & $\begin{array}{l}3.4 \\
10.3 \\
17.5 \\
44.8 \\
52.9 \\
24\end{array}$ \\
\hline Hospital stay & $\begin{array}{l}0-30 \mathrm{~min} \\
<6 \mathrm{hrs} \\
6 \text { to } 24 \mathrm{hrs} \\
>24 \mathrm{hrs}\end{array}$ & $\begin{array}{l}1 \\
2 \\
2 \\
24\end{array}$ & $\begin{array}{l}3.4 \\
6.8 \\
6.8 \\
83\end{array}$ \\
\hline Fetal Outcome & $\begin{array}{l}\text { Abortions } \\
\text { Undelivered } \\
\text { IUD } \\
\text { Live births - } \\
\text { (Term IUGR) } \\
\text { (Preterm) }\end{array}$ & $\begin{array}{l}1 \\
2 \\
5 \\
21- \\
(20) \\
(1)\end{array}$ & $\begin{array}{l}3.4 \\
6.8 \\
17.5 \\
72.4 \\
(69) \\
(3.4)\end{array}$ \\
\hline
\end{tabular}

Total number of maternal deaths: 29/14,220 live births; Maternal mortality ratio: 204; Intramural maternal mortality ratio (10/29): 70 ; Extramural maternal mortality ratio (19/29): 134

Table 2: Direct causes of maternal mortality.

\begin{tabular}{|llll|}
\hline Direct cause & Number & $\begin{array}{l}\text { Our } \\
\text { study }\end{array}$ & $\begin{array}{l}\text { WHO } \\
2010\end{array}$ \\
\hline $\begin{array}{l}\text { Hypertensive } \\
\text { disorders } \\
\text { complicating } \\
\text { pregnancies }\end{array}$ & 11 & $40 \%$ & $12 \%$ \\
\hline Haemorrhage & 9 & $31 \%$ & $25 \%$ \\
\hline Anaemia with failure & 5 & $17.2 \%$ & -- \\
\hline $\begin{array}{l}\text { Heart diseases } \\
\text { complicating } \\
\text { pregnancies }\end{array}$ & 2 & $6.4 \%$ & -- \\
\hline $\begin{array}{l}\text { Sepsis/unsafe } \\
\text { abortion }\end{array}$ & 1 & $3.2 \%$ & $13 \%$ \\
\hline Infection & -- & -- & $15 \%$ \\
\hline Obstructed labour & -- & -- & $8 \%$ \\
\hline Others & 1 & $3.2 \%$ & \\
\hline
\end{tabular}

There had been 29 maternal deaths amongst 14,220 live births over the study period Aug 2014 to July 2015 giving an maternal mortality ratio of 204 per 1,00,000 live births.

The majority of deaths were in the age group 20 to 29 years $-64.3 \%$

The majority of mothers with maternal death were from the lower socio economic strata $-75.7 \%$
$69.1 \%$ of mothers with maternal death were multi gravid with $85 \%$ having spacing less than 3 years especially the $20.6 \%$ unbooked mothers who were nomadic - $34 \%$ and illiterate $-20.6 \%$.

The primary antenatal care provider was found to be mainly Government Head Quarters Hospital 45\%; Primary Health Centres $30.9 \%$, i.e. $75.9 \%$ of cases were late referrals to our Institution.

The period of death was found to be postpartum $>24 \mathrm{hrs}$ in $76 \%$ of maternal deaths

The mode of delivery in woman with maternal death was found to be LSCS in $44.8 \%$ of patients and relaparotomy in $24 \%$ of patients. Peripartum hysterectomy was done in a total of $76.9 \%$ of patients.

The admission death interval was found to be beyond 24 hrs to 7 days in $83 \%$ of patients.

The contributory factors for maternal deaths were multiple referrals $24 \%$, lack of Intensive Care Unit, Specialist, Blood and blood products $-55.4 \%$ and familial and social factors in $31 \%$.

The direct causes of maternal deaths in our study was hypertensive disorders, complicating pregnancy - 40\%, haemorrhage $-31 \%$, anaemia with failure $-17.2 \%$, hear $\mathrm{t}$ diseases complicating pregnancy $-6.4 \%$, sepsis $-3.2 \%$, and other causes $3.2 \%$. 
The prominent indirect causes of death are - anemia in $13.6 \%$, sepsis - $17.5 \%$, epilepsy complicating pregnancy $6.8 \%$, cirrhosis with portal hypertension complicating pregnancy $-6.8 \%$, sigmoid injury $-3.4 \%$,
$72.4 \%$ of these maternal deaths, the fetal outcome were a live birth.

Table 3: Comparative analysis of direct causes of maternal deaths.

\begin{tabular}{|c|c|c|c|c|c|}
\hline Study & MMR & $\begin{array}{l}\text { Hypertensive disorders } \\
\text { complicating pregnancy (\%) }\end{array}$ & Haemorrhage (\%) & $\begin{array}{l}\text { Sepsis } \\
(\%)\end{array}$ & $\begin{array}{l}\text { Anaemia } \\
(\%)\end{array}$ \\
\hline Vidyadhar et al ${ }^{12}$ & 302.6 & 10.25 & 21.05 & 7.89 & 2.63 \\
\hline Bhaskar et al ${ }^{13}$ & 302.23 & 26.66 & 26.66 & 18.33 & 10 \\
\hline Boro $\mathrm{RC}$ et $\mathrm{al}^{14}$ & 463.9 & 19.23 & 25 & 9.6 & 28.85 \\
\hline Ritalal et $^{15}{ }^{15}$ & 1035 & 20 & 6.2 & 13.8 & 15 \\
\hline Sulthan $\mathrm{S}$ et $\mathrm{al}^{16}$ & 773 & 39.64 & 18.93 & 7.39 & 8.58 \\
\hline 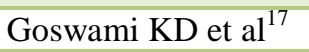 & 219 & 13 & 50 & 11 & 33 \\
\hline Mukherjee et al ${ }^{21}$ & 518.7 & 22.97 & 12.7 & 9.45 & 25.40 \\
\hline Puri et $\mathrm{al}^{22}$ & 690 & 18 & 12 & 24 & 13 \\
\hline Prashanta $\mathrm{R}$ et $\mathrm{al}^{23}$ & 625 & 50.56 & 9.22 & 18.17 & 4.8 \\
\hline Arpita $\mathrm{N}$ et $\mathrm{al}^{24}$ & 555.5 & 24.2 & 31.9 & 7.24 & 14.93 \\
\hline Verma Ashok et $\mathrm{al}^{25}$ & 348.9 & 20 & 21.8 & 21.6 & 15.4 \\
\hline Present study & 204 & 40 & 31 & 3.4 & 17 \\
\hline
\end{tabular}

\section{DISCUSSION}

In our present study, we found that the total maternal death in the one year study period from August 2014 to July 2015 is 29 amongst a total live birth of 14,220. Thus the maternal mortality ratio is 204 per 1,00,000 live births which is slightly higher than that of the maternal mortality ratio in India. The maternal mortality ratio in India dropped from 178 per 1,00,000 live births to 167 per 1,00,000 live births. ${ }^{2}$ The current maternal mortality ratio in Tamil Nadu is $79 .{ }^{4}$ The higher maternal mortality ratio in our study is because, ours is a tertiary level referral centre where critical and terminally ill cases are referred. Of the 29 maternal deaths in our study $34.4 \%$ are intramural deaths giving an intramural maternal mortality ratio of 70 per $1,00,000$ live births and $65.6 \%$ were extramural deaths due to late referrals in a critical condition giving an extramural maternal mortality ratio of 134 per 1,00,000 live births. Previous study in India and abroad have reported that the extramural maternal death range from 31.2 to $76.4 \%$ whereas in our study it is $65.6 \% .^{8-11}$ More higher mortality ratios had been found in the various studies - Vidhyadhar et al showing a maternal mortality ratio of 302.6, Baskar et al from 2011 showing a Maternal Mortality ratio of 302.23 , Boro RC et al from Assam - shows a Maternal Mortality ratio of 463.9 and Ritalal et al shows a very high maternal mortality ratio of 1035, Sulthan $S$ et al from Bhopal showing a high maternal mortality ratio of 773 , Goswamy KD et al from Rajkot, Gujarat has an almost equal maternal mortality ratio of $219 .^{12-17}$

The majority of deaths in our study were in the age group 20 to $29-64.3 \%$ which is in accordance with the age distribution of maternal death in India - MMR Bulletin of India 2011 to 2013 - where it is $68 \%$ in the age group 20 to 29 years. ${ }^{18}$ The majority of maternal deaths were from the lower socio economic strata $75.7 \%$ and $69.1 \%$ of these mothers were multi gravida with spacing less than 3 years especially the unbooked mothers who were nomadic and illiterate who not only have resource constraint but are also not self-empowered to take their own decisions or to understand the seriousness of their situation. These are the major risk factors of maternal mortality. $^{8}$

In our study the direct causes of maternal deaths are $40 \%$ hypertensive disorders complicating pregnancies, 30\% haemorrhage, Anemia with failure - 17.2\%, Heart disease complicating pregnancies - 6.8\%, Sepsis - 3.4\%, other causes $3.4 \%$. As per WHO $201013 \%$ of maternal deaths were due to hypertensive disorders complicating pregnancies, but in our study of the direct causes of maternal deaths, hypertensive disorders complicating pregnancies tops the list $-40 \% .^{3}$

Of these $40 \% 72.7 \%$ of maternal deaths were due to HELLP and its related complications and $37.3 \%$ were due to eclampsia. Intensive training of medical officers in PHCs and GH with efficient widespread use of magnesium sulphate and IV Labetalol, importance of taking blood pressure and urine albumin in every visit and treating anemia with iron sucrose and widespread auditing by state health society, the neurological complications of hypertensive disorders of pregnancies such as eclampsia has considerably decreased. ${ }^{19,20}$ But the $72.7 \%$ of patients with HELLP were brought late with irreversible shock with multiorgan dysfunction because 
of failure to identify the problem at earlier stages, too little or too late blood transfusion, non-availability of well-equipped blood bank, blood and blood products at $\mathrm{GH}$ were found to be the basic compounding factors in further increasing the maternal mortality rate due to gestational hypertension . But now as per NRHM guidelines and increased awareness by state health society, the early transfusion of blood and blood products for massive blood loss should done in the ratio of $6: 4: 1$ (packed cells transfusion : FFP : platelets) and well equipped blood bank is being made available in peripheral centres. ${ }^{19}$

Similar results with hypertensive disorders complicating pregnancies as the leading cause of maternal death have been found with Mukherjee et al $-22.97 \%$ of deaths due to toxaemia, Puri et al - $18 \%$, Prashantha R - 50.56\%, Ritalal et al - $20 \%$, Sulthan S et al also had increased maternal deaths due to gestational hypertension - $39.64 \%$, Bhaskar et al had an equal incidence of hypertension and haemorrhage as the cause of maternal death $26.66 \% .^{13,15,16,21-23}$

As per WHO 2010, 25\% of all maternal deaths are due to haemorrhage while in our study $31 \%$ of the maternal deaths were due to haemorrhage. ${ }^{3}$ Similar results had been found in various studies such as Arpita $\mathrm{N}$ et al has a $31.9 \%$ of deaths due to haemorrhage, Vidyadhar et al has a $21.05 \%$ of deaths due to haemorrhage, Verma A et al has a $21.8 \%$ of maternal death due to haemorrhage, Boro et al has $25 \%$ of maternal death due to haemorrhage. ${ }^{12,14,24}$ Bhaskar et al had an equal incidence of $26.66 \%$ of maternal deaths due to haemorrhage and toxaemia. $^{13}$

Goswamy KD et al has a $50 \%$ of maternal deaths due to haemorrhages. ${ }^{17}$ In our study, of the $31 \%$ of maternal deaths due to haemorrhage, $78 \%$ was found to be due to antepartum haemorrhage and $22 \%$ due to traumatic PPH. Of the, $78 \%$ due to antepartum haemorrhage, $40 \%$ was due to placenta accrete. With the SBA Guidelines for skilled attendance at birth, intensive training of medical officers PHCs, universal follow-up of AMTSL, widespread knowledge about PPH Management by NRHM, the incidence of Atonic, PPH is decreased. ${ }^{19,20}$

Placenta accreta is on the increase because of the increasing caesarean section rate. All these cases of placenta accrete were received post LSCS in bad shape with bleeding PV with irreversible shock. In 3 cases caesarean hysterectomy had already been done in Government Head Quarters Hospital and referred with DIC with irreversible haemorrhagic shock. Any LSCS with anterior placenta, we should have a high index of suspicion for placenta accreta as per RCOG Green top guidelines No.63 and adequate preparations should be made in anticipation. ${ }^{26}$ Ultra sonogram findings may help to suspect placenta accrete, viz., visualisation of irregular lakes with turbulent flow, abnormality of bladder wall, myometrial thickness less than $1 \mathrm{~mm}^{27}$
Severe anaemia with failure was found to be a direct determinant of maternal mortality in $17.2 \%$ of our study especially in nomadic illiterate multi gravid which reflects poor antenatal care and surveillance. Anaemia as a major cause of maternal deaths is also found in other studies as Mukherjee et al - $25.4 \%$, Boro RC et al $28.85 \%$, Bhaskar et al $-10 \%$, Arpita N et al $-14.95 \%$, Verma Ashok et al - 15.4\%. ${ }^{13,14,21,24,25}$

Rheumatic Heart disease still contributes as direct cause of maternal deaths in $6.4 \%$ in our study mainly tight mitral stenosis with acute pulmonary oedema. Mudaliar and Menons clinical obstetrics, heart disease complicating pregnancy accounts for $8.2 \%$ of direct causes of all maternal deaths. ${ }^{28}$ Sepsis due to unsafe abortion contributes to $3.2 \%$ of maternal deaths in our study. Obstructed labour and rupture uterus as a cause of maternal deaths is not seen in our study probably because of the strengthening of EMONC and CEMONC services. Efficient use of partogram, training of Anaesthetist skills, efficient audit by State Health Society. ${ }^{5,19,20}$

Facility based maternal death review and state based maternal death review conducted by State Health Society as per NRHM Guidelines gives aggregated data from which broader themes and trends can be identified and monitored and with appropriate policy changes and interventions has contributed a lot to the reduction of maternal mortality ratio in Tamil Nadu. ${ }^{29,30}$

\section{CONCLUSION}

The maternal mortality ratio in our study was 204/100,000 live births. Of these the maternal mortality ratio due to intramural deaths was 70/1,00,000 live births and maternal mortality ratio due to extramural deaths was $134 / 100,000$ live births. The cause of maternal death is the triad of hypertensive disorders complicating pregnancies, haemorrhage and anaemia.

Of these hypertensive disorders complicating pregnancies are the major cause of maternal deaths. Through widespread knowledge of importance of measuring blood pressure and urine albumin and widespread of magnesium sulphate, gestational hypertension is detected early and treated at Government Head Quarters Hospital. But other complications of gestational hypertension such as HELLP and Eclampsia are yet to be controlled. Inability to identify DIC at an earlier stage, under transfusion of blood and blood products and multiple referrals are found to be major cause of maternal deaths.

Empowerment of Government Head Quarters Hospital with blood products should be done. Anticipation of complications, early antenatal care, early referral, use of proper protocols is the key to prevention of maternal deaths. 


\section{ACKNOWLEDGEMENTS}

I gratefully acknowledge and express my sincere thanks to our Dean, Thanjavur Medical College and hospital, Thanjavur, Tamilnadu, India for allowing me to do this study and utilizing the Institutional facilities. I would also like to thank all the medical and para-medical staffs who have helped me complete this study. I would like to thank all my colleagues and friends who have been a constant source of encouragement to me. My co- author Dr. M. Poovathi read and approved the final manuscript.

Funding: No funding sources

Conflict of interest: None declared

Ethical approval: The study was approved by the Institutional Ethics Committee

\section{REFERENCES}

1. Health Statistics and Information systems WHO 2015. Available from http://www/who.int/healthinfo/statistics/indmaternal mortality/en/. Last accessed on August 23, 2015.

2. Government of India. Maternal Mortality in India 2011-2013. New Delhi; Registrar General, India 2013.

3. WHO, UNICEF, UNFPA, the World Bank. Trends in Maternal Mortality; 1990 to 2010. WHO, UNICEF, UNFPA and The World Bank estimates. Geneva; WHO, UNICEF, UNFPA; 2012.

4. Government of India. Maternal Mortality in India 2012-2014. New Delhi; Registrar General, India 2014.

5. NRHM - SHS - TN - Proc. No.6326/P5/SHS/2013. RCH - PIP 2014, Ministry of Health and Family Welfare, Maternal Death Review - $\mathrm{Pb}$ nrhm.org/docs/mdr.pdf.

6. Dumont A, Gaye A, Landry A. FBMDR: effects on Maternal Mortality in a District Hospital in Senegal. Bull WHO. 2006:84:218-24.

7. Lewis G. Beyond the numbers: reviewing Maternal Death and complications to make pregnancy safer. Br. Med Bull. 2003;67:27-37.

8. Tayade S, Bagde M, Shivkumar P, Tayade A, Bagde N. Maternal Death Review to know the determinants of Maternal Mortality in a District Hospital of Central India, Internet Dig of Biomed Res. 2012:3(3).

9. Rajaram P, Agarwal A, Swain S. Determinants of Maternal Mortality: a hospital based study from South India. Indian Journal of Maternal and Child Health. 1995;6(1):7-10.

10. Bedi N, Kambo I, Dhillon BS. Maternal Death in India - Preventable Tragedies (An ICMR Task Force Study. J Obstet Gynecol. 2001;51(2):86-92.

11. Kongnyuy EJ, M lava G. FBMDR in 3 districts in Central Region of Malawi; an analysis of causes and characteristics of Maternal Death. Women's Health. 2009;19(1):14-20.
12. Vidhiyadhar B, Purushottam A, Giri B, GargRc. Maternal Mortality at a tertiary care teaching hospital of rural India, a retrospective study. Int J Biool Med Res. 2001;2(4):1043-6.

13. Murthy BK, Murthy MB, Prabhu PM. Maternal Mortalityin a tertiary care hospital: A 10 - year review. Int J Prev Med. 2013;4:105-9.

14. Boro RC, Sarma P, Acharjee PS. Causes of maternal deaths at Tezpur Medical College and Hospital $(\mathrm{TMCH})$, Tezpur, Assam, India: a retrospective study. Int J Reprod Contracept Obster Gynecol. 2016;5:1006-9.

15. Lal R, Lal S, Mandal A. Births Should not cause deaths: A retrospective analysis of Maternal Mortality at a Tertiary care Hospital in Eastern India. Int J of Scientific study. 2015;3(8):67-70.

16. Sultan S, Kumar A, Bhagchandani D. Analysis of Maternal Mortality in Tertiary Care Centre: A retrospective study. $\mathrm{J}$ of Evolution of Medical and Dental Sciences. 2013;2(11):1728-35.

17. Goswami KD, Dudhrejia KM, Parmar PH, Kataria A. An analytical study of Maternal death at Tertiary Care Hospital. Int. J Med Res Rev. 2015;3(9):100811.

18. Distribution of Maternal and Neonatal Deaths India 2011-13 - MMR Bulletin 2011-13, Registrar General of India - Sample Registration System.

19. NRHM Guidelines. Availbale from: www.nrhm.gov.in/nrhmcomponents/reproductive child health/ maternal health.htm /SBA guidelines.

20. Gopalan S, Ratnakumar S, Jain V. Mudaliar and Menon's Clinical Obstetrics. 12th edition editors. 2011. pp. 469-73.

21. Mukherjee S, Theengh C, Bhattacharya S, Maru I. Maternal Mortality at a tertiary care institute of Central India. Asian J of Obst Gynec. 2010;4:23-7.

22. Puri A, Yadav I, Jain N. Maternal Mortality in an urban tertiary care hospital of North India. Indian J of Obst Gynecol. 2011;61(3):280-5.

23. Pal A, Prasantha R, Samir H, Mondal TK. Review of changing trends in material mortality in a rural medical college of West Bengal. J Obst Gynecol Ind.2005;55(6):521-4.

24. Arpita N. A retrospective and prospective study of maternal mortality in a rural tertiary care hospital of Central India. Indian $\mathrm{J}$ of community Health 2013;25:1.

25. Verma A, Minhas S, Sood A. A study on maternal mortality in Dr. Rajendra Prasad Govt. M.C. Tanda Dist. Kangra, HP. Indian J Obst Gynecol. 2008;58(3):226-9.

26. Antepartum Haemorrhage, Clinical Green top guidelines No.63. The Royal College of Obstetricians and Gynecologists. Nov 2011.

27. Comstock CH. Antenatal diagnosis of placenta accreta: a review. Ultrasound Obstet Gynecol. 2005;26:89-96.

28. Gopalan S, Ratnakumar S, Jain V. Mudaliar and Menon's Clinical Obstetrics. 12th edition editors. 2011. pp. 413-18. 
29. Farquhar C, Sadler L, Masson V. et al Beyond the numbers: classifying contributory factors and potentially available maternal death in New Zealand. 2006-09. AMJ Obstet Gynecol. 2011:205:331.el.8.
30. Sandhu AK, Mustafa FE. Maternal Mortality in Bahrain 1987-2004, an audit of causes of avoidable death. East Mediter Health J. 2008;14(3):720-30.

Cite this article as: Rajarajeswari R, Poovathi $\mathrm{M}$. Make every mother and child count - a retrospective analysis of maternal mortality at medical college tertiary care hospital, Tamilnadu, India. Int J Reprod Contracept Obstet Gynecol 2016;5:3864-70. 